Article

\title{
Cultivar Dependent Impact on Yield and Its Components of Young Almond Trees under Sustained-Deficit Irrigation in Semi-Arid Environments
}

\author{
Saray Gutiérrez-Gordillo ${ }^{1, *} \mathbb{0}$, Víctor Hugo Durán Zuazo ${ }^{2} \oplus$, Virginia Hernández-Santana ${ }^{3}$, \\ Fernando Ferrera Gil ${ }^{1}$, Amelia García Escalera ${ }^{1}$, José Juan Amores-Agüera ${ }^{1}$ and \\ Iván Francisco García-Tejero ${ }^{1}$ D \\ 1 Instituto Andaluz de Investigación y Formación Agraria y Pesquera (IFAPA), Centro "Las Torres", \\ Carretera Sevilla-Cazalla Km 12.2, 41200 Sevilla, Alcalá del Río, Spain; \\ fernandoferreragil@icloud.com (F.F.G.); ameliagaes7@gmail.com (A.G.E.); \\ josej.amores@juntadeandalucia.es (J.J.A.-A.); ivanf.garcia@juntadeandalucia.es (I.F.G.-T.) \\ 2 Instituto Andaluz de Investigación y Formación Agraria y Pesquera (IFAPA), Centro "Camino de Purchil", \\ Camino de Purchil s/n, 18004 Granada, Spain; victorh.duran@juntadeandalucia.es \\ 3 Instituto de Recursos Naturales y Agrobiología de Sevilla, Consejo Superior de Investigaciones Científicas, \\ Avda. Reina Mercedes 10, 41012 Sevilla, Spain; virginiahsa@irnas.csic.es \\ * Correspondence: saray.gutierrez@juntadeandalucia.es; Tel.: +34-671532852
}

Received: 9 April 2020; Accepted: 18 May 2020; Published: 20 May 2020

check for updates

\begin{abstract}
Almond (Prunus dulcis Mill. (D.A. Webb)) plantations in irrigated semi-arid areas need to successfully face the new scenarios of climate change combining sustainable irrigation strategies and tolerant cultivars to water stress. This work examines the response of young almond (cvs. Guara, Marta, and Lauranne) subjected to different irrigation doses under semi-arid conditions (South-West Spain). The trial was conducted during two seasons (2018-2019) with three irrigation strategies: A full-irrigated treatment (FI), which received $100 \%$ of the irrigation requirements (IR), and two sustained-deficit irrigation strategies that received 75\% (SDI $\left.{ }_{75}\right)$ and $65 \%\left(\mathrm{SDI}_{65}\right)$ of IR. Crop water status was assessed by leaf water potential $\left(\Psi_{\text {leaf }}\right)$ and stomatal conductance $\left(g_{s}\right)$ measurements, determining the yield response at the end of each season. Different physiological responses for the studied cultivars were observed, especially considering the $\Psi_{\text {leaf }}$ measurements. In this way, $c v$. Marta behaved more tolerant, while cvs. Guara and Lauranne maintained higher $g_{s}$ rates in response to water stress. These differences were also observed in terms of yield. The $c v$. Lauranne did not reflect yield losses, and the opposite trend was observed for $c v$. Guara, in which reductions on fruit numbers per tree were detected. On overall, effective irrigation water savings $\left(\approx 2100 \mathrm{~m}^{3} \cdot \mathrm{ha}^{-1}\right.$ in $\mathrm{SDI}_{65}$ ) could be feasible, although these responses are going to be substantially different, depending on the used cultivar.
\end{abstract}

Keywords: almond cultivars; crop physiological response; irrigation water productivity; nut yield

\section{Introduction}

Today, deficit irrigation (DI) strategies cannot be considered as a novelty, and their effects and consequences have been widely studied in order to improve water resources management under water shortage conditions. With them, irrigation can be reduced until certain levels, with the main aim of maximizing the water savings keeping the yields within an acceptable range, close to those obtained under non-water restrictions [1]. Several authors have reported positive results when these 
strategies have been applied in different woody crops, many times with promising results of water savings, low yield reductions [2], and even improvements on fruit quality [3-5]. Although almond is a well-known drought-tolerant crop [6], water availability is the main restricting factor in semi-arid environments, determining the nut yield and its components (kernel unit weight and fruit numbers per tree) [7]. Moreover, yield reductions are not exclusively affected by the water stress but also the DI practice imposed; among them; regulated deficit irrigation (RDI), sustained-deficit irrigation (SDI), partial root-zone (PRD), or low-frequency deficit irrigation (LFDI) [8]. RDI and SDI are the most studied strategies; the first one, characterized by applying a smaller amount of water in that period in which the crop is less sensitive to this withholding of water [9], whereas SDI consists of applying a sustained water reduction throughout the growth cycle [10]. Very promising results have been obtained when LFDI is applied during the kernel-filling period, without yield losses even under long-term experiences [11]. This DI strategy consists of applying irrigation-restriction cycles which are derived by means of physiological threshold values previously defined. Thus, its application has the disadvantage of requiring proper crop water monitoring, which many times results in being very difficult for farmers and technicians. Finally, in PRD strategies, part of the root system is exposed to drying soil while the remaining part is irrigated normally [12], and in the case of almond, its application has not improved the obtained results in comparison to RDI or SDI treatments that had received similar irrigation amounts [13].

Currently, the RDI is the most-studied strategy for the case of almond and many authors have described its response under different water stress levels [9,14-16], but there are few works about the response of almond trees to SDI. In this sense, Egea et al. [17] compared the response of almond ( $c v$. Marta) productivity to different irrigation strategies, reporting yield reductions of $12 \%$ and water savings of 37\% with SDI strategy. Phogat et al. [18] evaluated the response of soil plant system in cos. Nonpareil, Carmel and Ne Plus Ultra under SDI, obtaining that water uptake efficiency was substantially higher under SDI, compared to normal application conditions. Other authors [19] have evaluated the financial viability of applying SDI or RDI, concluding that SDI was the strategy that allowed greater savings in financial terms.

Not only the DI strategy is determinant, but also the almond cultivar, because the response to water stress could be different among them [20,21]. In this sense, Gómez-Laranjo et al. [22] studied the differences in terms of physiological response of five almond cultivars (cvs. Lauranne, Masbovera, Ferragnès, Francoli, and Glorieta) under full-irrigated and rainfed situations. This author concluded that $c v$. Lauranne and Francoli were the less sensitive to irrigation withholdings. Moreover, Oliveira et al. [23] studied leaf anatomy changes and water relations in five traditional cultivars (cvs. Bonita, Casanova, Parada, Pegarinhos, and Verdeal) and two commercial (cvs. Ferragnès and Glorieta), highlighting $c v$. Ferragnès as most sensitive cultivar to drought conditions. This fact was associated with low values for cuticle and for the ratio between palisade and spongy parenchyma; as well as higher values of vulnerability index, conducting vessels area, or xylem area. Yadollahi et al. [24] apprised that six almond genotypes had different reactions to water stress, displaying the ability to tolerate moderate and severe water stress conditions. In addition, Barzegar et al. [25] studied the responses of six almond cultivars (cvs. Azar, Marcona, Mission, Nonpareil, Sahand, and Supernova) to water stress, reporting as less sensitive cos. Supernova and Azar in contrast to cvs. Marcona and Sahand. More recently, Gutiérrez-Gordillo et al. [26] analyzed the yield of three almond cultivars (cvs. Guara, Marta, and Lauranne) under RDI and over irrigated conditions, revealing that, although no significant reductions were observed between full irrigation and RDI; $c v$. Marta offered significant improvements in terms of yield and physiological response when this cultivar received irrigation doses around $150 \%$ of crop evapotranspiration, this response not being observed in the remaining cultivars.

In summary, plants' reactions to water stress are complex, implicating adaptive changes and/or detrimental consequences, and the different responses are regulated by the innate plant features as well as the duration and intensity of the imposed stress. In this line, we hypothesize that under water stress almond cultivars are able to exhibit different tolerance levels, and the physiological reactions could be 
divergent in response to SDI strategies, which ultimately effects on yield and its components. Thus, the aim of this study was to assess the nut yield and physiological response of three commercial almond cultivars namely Guara, Marta, and Lauranne subjected to sustained-deficit irrigation strategies, elucidating the tolerant cultivar under these strategies in a semi-arid Mediterranean environment.

\section{Materials and Methods}

\subsection{Experimental Site}

The trial was conducted during two consecutive years (2018-2019) in a commercial almond orchard (Prunus dulcis Mill. (D.A. Webb) cvs. Guara, Marta, and Lauranne (Figure 1); grafted onto GN15 rootstock), and located in the Guadalquivir river basin (SW Spain, 37 $30^{\prime} 27.4^{\prime \prime} \mathrm{N}, 5^{\circ} 55^{\prime} 48.7^{\prime \prime} \mathrm{W}$ ). Trees were planted in 2013, spaced $8 \times 6 \mathrm{~m}$, and drip irrigated using two pipelines with emitters of $2.3 \mathrm{~L} \cdot \mathrm{h}^{-1}$, at $0.75 \mathrm{~m}$ intervals. Canopy volumes were very similar within each cultivar. That is, for $c v$. Marta, canopy volumes ranged from 64 to $65 \mathrm{~m}^{3}$; for $c v$. Guara between 65 and $66 \mathrm{~m}^{3}$; and for the case of $c v$. Lauranne, some higher than the previous cultivars, with canopy volumes between 72 and $74 \mathrm{~m}^{3}$.

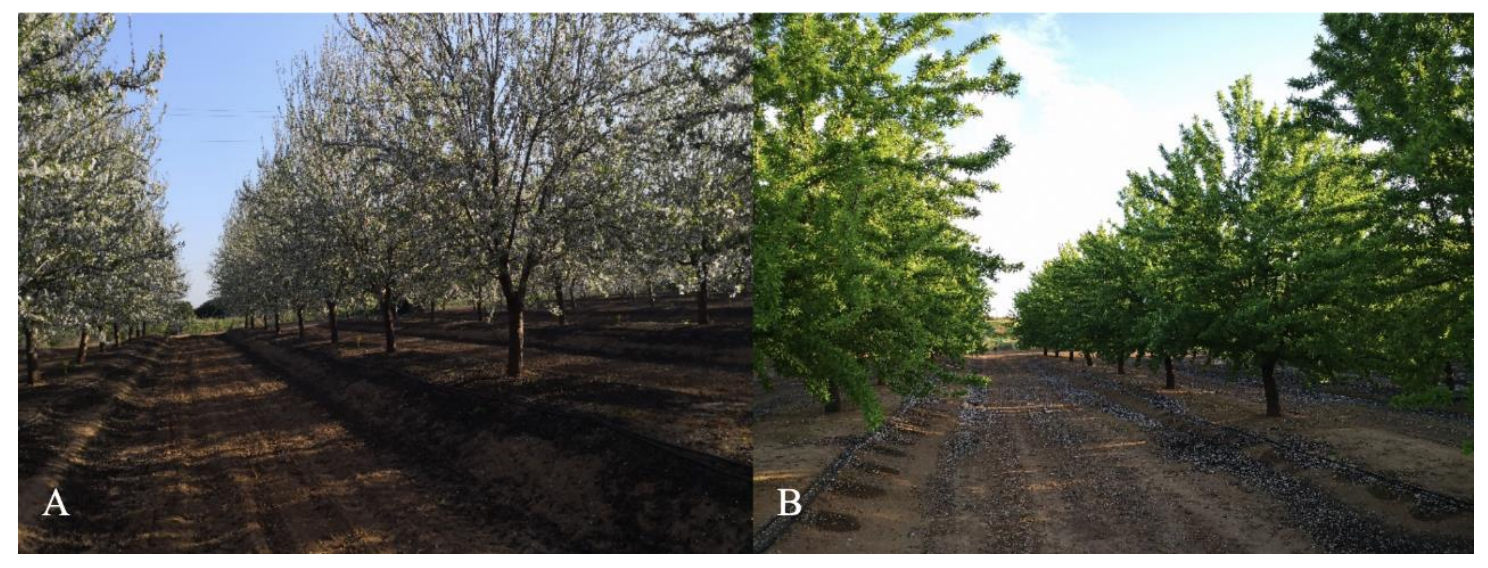

Figure 1. Experimental plot. Flowering (A) and vegetative (B) phenological period.

The soil is a silty loam typical Fluvisol, more than $2 \mathrm{~m}$ deep, with organic matter $<1.5 \%$. Roots were located predominately in the first $50 \mathrm{~cm}$ soil depth, corresponding to the intended wetting depth. Soil water content values at field capacity $(-0.033 \mathrm{MPa})$ and permanent wilting point $(-1.5 \mathrm{MPa})$ were close to 0.40 and $0.15 \mathrm{~m}^{3} \cdot \mathrm{m}^{-3}$, respectively. The climatic classification of the study area is attenuated meso-Mediterranean, with an annual $\mathrm{ET}_{0}$ rate of $1400 \mathrm{~mm}$ and accumulated rainfall of $540 \mathrm{~mm}$ (average data corresponding to the last 15 years; obtained from the Andalusian Weather information Network [27]).

Regarding to the experimental conditions registered in the irrigation period (from March to October) during the monitored years, in 2018 the average temperature was $20.5^{\circ} \mathrm{C}$ with minimum and maximum average temperatures of 7.3 and $37.7^{\circ} \mathrm{C}$, respectively. Similarly, during the second year (2019), the average temperature was $25^{\circ} \mathrm{C}$ with minimum and maximum average values of 7.2 and $36.5^{\circ} \mathrm{C}$, respectively. In relation to the average vapor pressure deficit (VPD) in 2018 it ranged from 1.20 to $3.36 \mathrm{KPa}$, while during 2019 it was between 1.10 and $2.49 \mathrm{KPa}$. Reference evapotranspiration $\left(\mathrm{ET}_{0}\right)$ and rainfall during the irrigation period (March-October) amounted to 1102 and $326 \mathrm{~mm}$ for 2018, meanwhile, in the second year $\mathrm{ET}_{0}$ and rainfall were 1221 and $85 \mathrm{~mm}$, respectively. Crop evapotranspiration $\left(\mathrm{ET}_{\mathrm{C}}\right)$ rates for both seasons averaged $860 \mathrm{~mm}$, which was in line with previous reports by López-López et al. [28] or García-Tejero et al. [11] who estimated water requirements of 800 and $900 \mathrm{~mm}$ for mature almond trees in Guadalquivir river basin. 


\subsection{Irrigation Treatments}

Three irrigation treatments were designed; (i) a full-irrigated treatment (FI), which received $100 \%$ of irrigation requirements (IR) during the irrigation period, (ii) a sustained-deficit irrigation $\left(\mathrm{SDI}_{75}\right)$ treatment, which received $75 \% \mathrm{IR}$, and (iii) a sustained-deficit irrigation $\left(\mathrm{SDI}_{65}\right)$ treatment, which received $65 \%$ IR.

In both seasons, irrigation was applied from the middle of March to the end of October, the IR being estimated according to the methodology proposed by Allen et al. [29] (Equations (1) and (2)), obtaining the values of reference evapotranspiration $\left(\mathrm{ET}_{0}\right)$ by using a weather station installed in the same experimental orchard (Davis Advance Pro2, Davis Instruments, Valencia, Spain).

$$
\begin{gathered}
\mathrm{ET}_{\mathrm{C}}=\mathrm{K}_{\mathrm{C}} \times \mathrm{K}_{\mathrm{r}} \times \mathrm{ET}_{0} \\
\mathrm{IR}(\mathrm{mm})=\left(\mathrm{ET}_{\mathrm{C}}-\text { Rainfall }\right)
\end{gathered}
$$

where $\mathrm{ET}_{\mathrm{C}}$ is the crop evapotranspiration; $\mathrm{K}_{\mathrm{C}}$ is the single-crop coefficient; $\mathrm{K}_{\mathrm{r}}$ is the crop reduction coefficient, which depends on the percentage of shaded area cast by the tree canopy; $\mathrm{ET}_{0}$ is the reference evapotranspiration; and IR is the irrigation requirements.

The local crop coefficients used during the experimental period ranged from 0.4 to 1.2 according to García-Tejero et al. [30]. Additionally, the IR was reduced for $\mathrm{SDI}_{75}$ and $\mathrm{SDI}_{65}$ by multiplying it by 0.75 and 0.65 , respectively.

According the climatic conditions the irrigation doses received for $\mathrm{FI}, \mathrm{SDI}_{75}$ and $\mathrm{SDI}_{65}$ during 2018 were 4974,3713 and $3342 \mathrm{~m}^{3} \cdot \mathrm{ha}^{-1}$; and during 2019; 7700, 5744 and $5159 \mathrm{~m}^{3} \cdot \mathrm{ha}^{-1}$, respectively.

\subsection{Plant Measurements}

During the maximum evapotranspirative demand period, coinciding with the kernel-filling and pre-harvest stages (from early June to mid-August; 160-225 DOY in 2018; and 160-219 DOY in 2019), crop-water monitoring was done by means of measurements of leaf water potential $\left(\Psi_{\text {leaf }}\right)$ and the stomatal conductance to water vapor $\left(g_{s}\right)$; these readings being taken between 12:00 and 13:30 GTM, and with a periodicity of 10-15 days. The $\Psi_{\text {leaf }}$ was measured using a pressure chamber (Soil Moisture Equipment Corp., Sta. Barbara, CA, USA), monitoring 8 trees per irrigation treatment and two leaves per tree, located in the north side of the tree and being totally mature, fresh and shaded; at $1.5 \mathrm{~m}$ of height, approximately and NW exposed. In these same trees, we measured the $g_{s}$, using a porometer SC-1 (Decagon Devices, INC, Pullman, WA, USA), these measurements being done in two leaves per monitored tree, completely exposed to the sun, at $1.5 \mathrm{~m}$ of height, and preferably with south-eastern facing.

Additionally, with the aim of quantifying total water stress supported by the crop, the stress integral (SI) was calculated from $\Psi_{\text {leaf }}$ and $g_{s}$ data, following the methodology proposed by Myers et al. [31] (Equations (3) and (4)):

$$
\begin{aligned}
S I_{\text {leaf }} & =\left|\sum\left(\Psi_{\text {leaf }}^{a v}-\Psi_{\text {leaf }}^{\text {max }}\right) \times n\right| \\
S I_{g s} & =\sum\left(g_{s s}^{a v}-g_{s}^{\text {min }}\right) \times n
\end{aligned}
$$

where $S I_{\text {leaf }}$ is the stress integral in terms of leaf-water potential values, $\Psi_{\text {leaf }}^{\text {av }}$ is the average leaf water potential for any interval; $\Psi_{\text {leaf }}^{\max }$ is the maximum value of leaf-water potential registered during the experimental period; $S I_{g s}$ is the stress integral in terms of stomatal conductance values, $g_{s}^{a v}$ is the average stomatal conductance for any interval; $g_{s}^{\min }$ is the minimum value of stomatal conductance during the experimental period; and $n$ is the days numbers within each interval.

According to these indexes, higher water stress gathered by the crop would be related to higher values of $S I_{\text {leaf }}$ and lesser values of $S I_{g s}$. In this sense, these indexes provide information to quantify the crop water stress accumulated along a period, allowing quantifying the effect of water restriction 
beyond its temporal distribution, integrating the global stress supported by the crop in comparison to the punctual measurements.

At the end of each season it was monitored the almond yield in terms of nut and kernel weight. Harvesting was carried out by using a mechanical vibrator with a mechanical peeling to remove the hull. Once cleaned, almonds were left to air dry and weighed once they reached a humidity content of around $6 \%$. Finally, almonds were processed with shelling machine, obtaining the kernel yield for each irrigation treatment and cultivar.

In relation to the harvesting dates these were different for each cultivar and season. In 2018, the almond harvest labors were done at 232 DOY for $c v$. Guara and 239 DOY for cvs. Marta and Lauranne; meanwhile in 2019, these were done at 219, 221, and 235 DOY for Guara, Marta, and Lauranne, respectively.

Taking into consideration that two components determines the yield (the almond size and number of almonds per tree); the first one was obtained by weighing 100 almonds per monitored tree $(n=8)$; obtaining the kernel unit weight and ratio between kernel and nut (kernel + shell). After this, the second component (number of almonds per tree) was estimated by dividing "the kernel yield per monitored tree" by "the kernel unit weight", tracing the most affected yield component by water stress imposed in each cultivar.

Finally, and considering the total irrigation applied in each treatment, it was estimated the irrigation water productivity (IWP; $\mathrm{kg} \cdot \mathrm{m}^{-3}$ ), defined as the ratio between kernel yield and irrigation, water applied.

\subsection{Experimental Design and Stadistical Analysis}

The experimental design was of randomized blocks, with four replications per irrigation treatment and cultivar. Each replication had 12 trees ( 3 rows and 4 trees per row), and the two central trees for each replication were monitored. Thus, eight trees per treatment of irrigation strategy were monitored $(n=8)$.

Statistical analysis was developed by using the Sigma Plot statistical software (version 12.5, Systat Software, Inc., San Jose, CA, USA) and the SPSS software (SPSS Inc., 15.0 Statistical packages; Chicago, IL, USA). Year-to-year, an exploratory descriptive analysis of the whole of physiological measurements ( $\Psi_{\text {leaf }}$ and $g_{s}$ ) for each treatment and cultivar was done; applying a Levene's test to check the variance homogeneity of the variables studied. After this, for each cultivar, an ANOVA for repeated measures was developed (three treatments and 2 freedom degrees), applying a Bonferroni test to compare pairs of treatments when significant differences in the ANOVA were detected. Moreover, and with the aim of identifying those days in which differences between irrigation treatments were detected, a one-way analysis of variance (ANOVA) and a Tukey's test were done for each measurement day.

Additionally, considering the results provided by $S I_{g s}$ and $S I_{\text {leaf }}$; for each irrigation treatment and cultivar, a two-way ANOVA was developed, followed by a Tukey's multiple range test. These results allow development of a simpler statistical analysis (considering that all measurements were transformed into an stress index that summarizes the total water stress accumulated by the crop) and to find a single value to evaluate the water stress supported by each cultivar and irrigation treatment and to analyze the hypothetical differences between cultivars and treatments in physiological terms with ease. Moreover, the linear regressions between the average values of $S I_{\text {leaf }}$ and $S I_{g s}$ registered for each treatment in both years were obtained $(n=6)$, applying an analysis of covariance (ANCOVA) to evaluate the differences in the interception points and slopes of these regressions. These analyses would allow the determination of whether these relationships are cultivar dependent and if this dependence is accompanied by similar yield responses.

Finally, and year-to-year, the kernel yield and its components were analyzed (kernel unit weight, the ratio between kernel weight vs. almond weight (kernel + shell), and fruits number per tree); by applying a Levene's test to check the variance homogeneity and ANOVA with a Tukey's test, considering as factors, the irrigation treatment, the cultivar, and their interactions. 


\section{Results and Discussion}

\subsection{Physiological Response to Water Stress}

In the course of the first experimental season (2018) the ANOVA for repeated measures did not show significant differences between irrigation treatments within each cultivar. That is, on overall as $\Psi_{\text {leaf }}$ as $g_{s}$ evidenced similar results for the studied treatments; although afterwards, the analysis done independently for each monitoring day reflected significant differences between treatments. These differences between treatments were especially noticeable for the case $\Psi_{\text {leaf }}$ (Figure 2), in comparison to the higher similarities reported by $g_{s}$ measurements (Figure 3). When confronting the $\Psi_{\text {leaf }}$ values registered in each cultivar, these ranged from -0.9 to $-2.3 \mathrm{MPa}$ for cos. Guara and Lauranne, meanwhile for $c v$. Marta these ranged between -0.8 and $-2.0 \mathrm{MPa}$.

In relation to $g_{s}$, the obtained values between treatments and cultivars were very similar, which was very evident by the absence of significant differences. Comparing the $g_{s}$ values for each cultivar, $c v$. Guara showed values between 80 and $175 \mathrm{mmol} \cdot \mathrm{m}^{-2} \cdot \mathrm{s}^{-1}, c v$. Marta between 75 and $180 \mathrm{mmol} \cdot \mathrm{m}^{-2} \cdot \mathrm{s}^{-1}$, and $c v$. Lauranne registered $g_{s}$ rates between 90 and $175 \mathrm{mmol} \cdot \mathrm{m}^{-2} \cdot \mathrm{s}^{-1}$.

As happened in 2018, during 2019 the differences among treatments were higher in $\Psi_{\text {leaf }}$ than in $g_{s}$. (Figure 2). Again, the ANOVA for repeated measures did not reflect significant differences between irrigation treatments. For $c v$. Guara, $\Psi_{\text {leaf }}$ values ranged from -1.4 to $-1.9 \mathrm{MPa}$ in FI, whereas in SDI treatments these values oscillated from -1.7 to $-2.5 \mathrm{MPa}$. Somewhat lower were the values for $c v$. Lauranne with $\Psi_{\text {leaf }}$ between -1.1 and $-1.7 \mathrm{MPa}$ in $\mathrm{FI}$, and for both $\mathrm{SDI}_{75}$ and $\mathrm{SDI}_{65}$ between -1.5 and -2.0 MPa. Also, some differences for $c v$. Marta were observed with $\Psi_{\text {leaf }}$ with values between -1.1 and $-1.6 \mathrm{MPa}$ in FI; and for both SDI treatments between -1.3 and $-1.9 \mathrm{MPa}$. In relation to $g_{s}$ in 2019, no significant differences among treatments were observed for any studied cultivar (Figure 3), very similar to that reported in the previous season. In particular, for $c v$. Guara, the $g_{s}$ rates were between 163 and $314 \mathrm{mmol} \cdot \mathrm{m}^{-2} \cdot \mathrm{s}^{-1}$ whereas $c v$. Lauranne displayed similar rates between 161 and $275 \mathrm{mmol} \cdot \mathrm{m}^{-2} \cdot \mathrm{s}^{-1}$. Finally, $c v$. Marta registered $g_{s}$ values that ranged from 150 to $310 \mathrm{mmol} \cdot \mathrm{m}^{-2} \cdot \mathrm{s}^{-1}$, these being similar in all studied irrigation treatments.

In summary and considering the observed values during the two studied years, $c v$. Marta showed a higher capability to register higher values for $\Psi_{\text {leaf }}$ with respect to the other remaining studied cultivars, especially under SDI conditions.

More perceptible findings were achieved in relation to the water stress integral (Table 1$)$. During the first experimental season (2018) significant effects in relation to cultivar $(p<0.05)$ were found in $S I_{\Psi l e a f}$ and $S I_{g s}$. In this sense, cvs. Guara and Lauranne showed similar values of SIYleaf and $S I_{g s}$, and significant $(p<0.05)$ higher than those calculated in $c v$. Marta. Particularly noticeable were the values of $S I_{g s}$ for $c v$. Marta, which were, globally, 38\% and 30\% lower than those registered in cvs. Lauranne and Guara, respectively. Respect to the irrigation doses effects, no significant differences were observed for $S I_{\Psi l e a f}$ and $S I_{g s}$, this being in agreement with the absence of differences reported by the ANOVA for repeated measured previously discussed.

During 2019, the highest differences were observed again among cultivars, as for $S I_{\Psi l e a f}$ as for $S I_{g s}$. Thus, the lowest and highest values of $S I_{\Psi l e a f}$ were reached by cvs. Marta and Guara, respectively, very similar to the response observed the previous season. Moreover, the highest differences in 2019 were determined in $S I_{g s}$ among cultivars, with values for cvs. Guara and Lauranne higher that those obtained for $c v$. Marta $(p<0.01)$. That is, irrigation doses did not promote differences in SIYleaf (as the previous season), different to the observed in $S I_{g s}$ with values for $\mathrm{SDI}_{65} 20 \%$ higher than those detected in FI.

Taking into account the interaction between both considered factors (irrigation $\times$ cultivar), these were detected only the second studied year, as for $S I_{\Psi l e a f}$ as for $S I_{g s}$, the cultivar being the main factor of this interaction. More interesting were the relationships between the $S I_{\text {leaf }}$ and $S I_{g s}$, which were estimated for each cultivar (Figure 4). Whereas cos. Guara and Lauranne showed similar relationships, and the ANCOVA did not reveal differences for the intercepts and slopes between both cultivars; 
significant differences were registered with the interception point obtained in $c v$. Marta, although the slopes were very similar.

2018
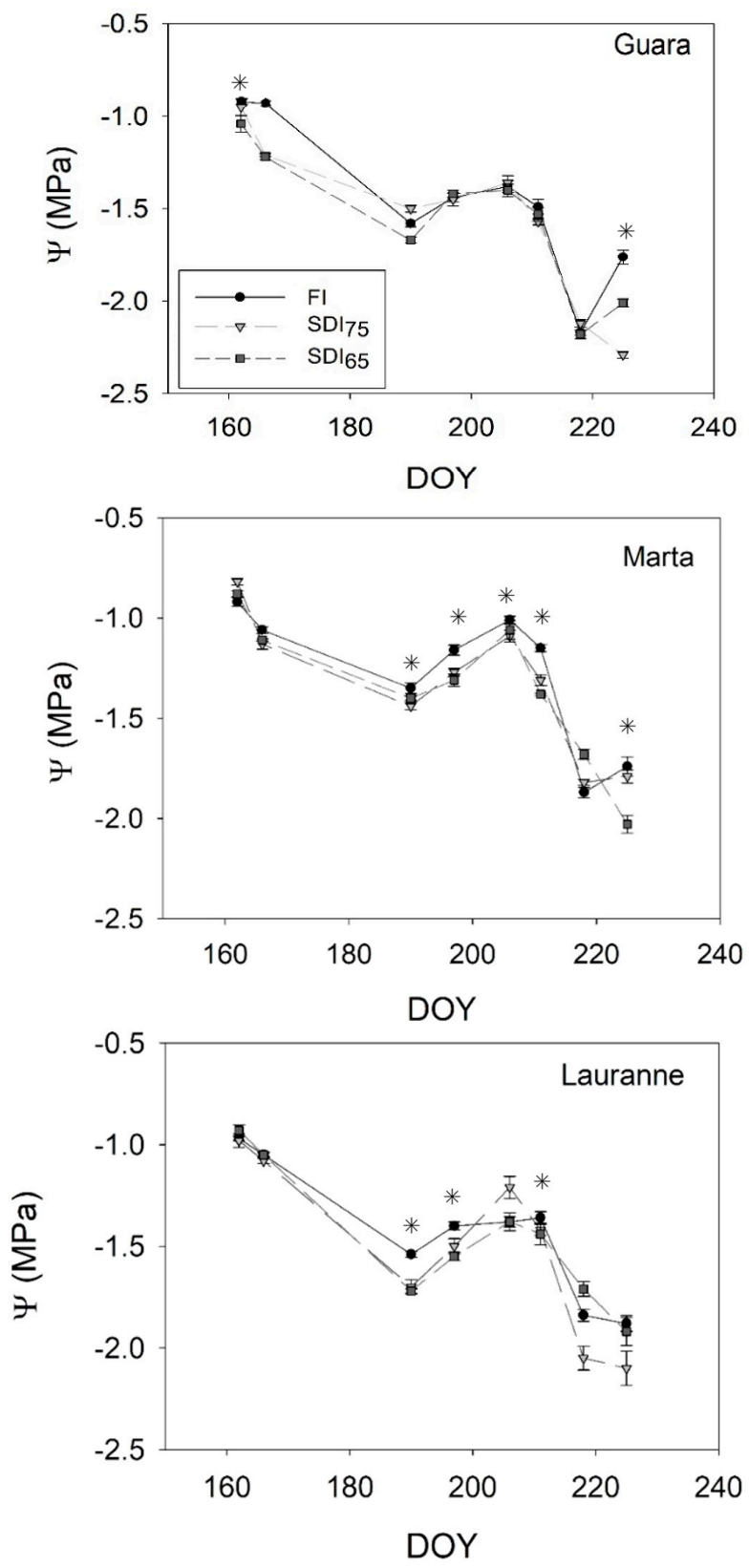

2019
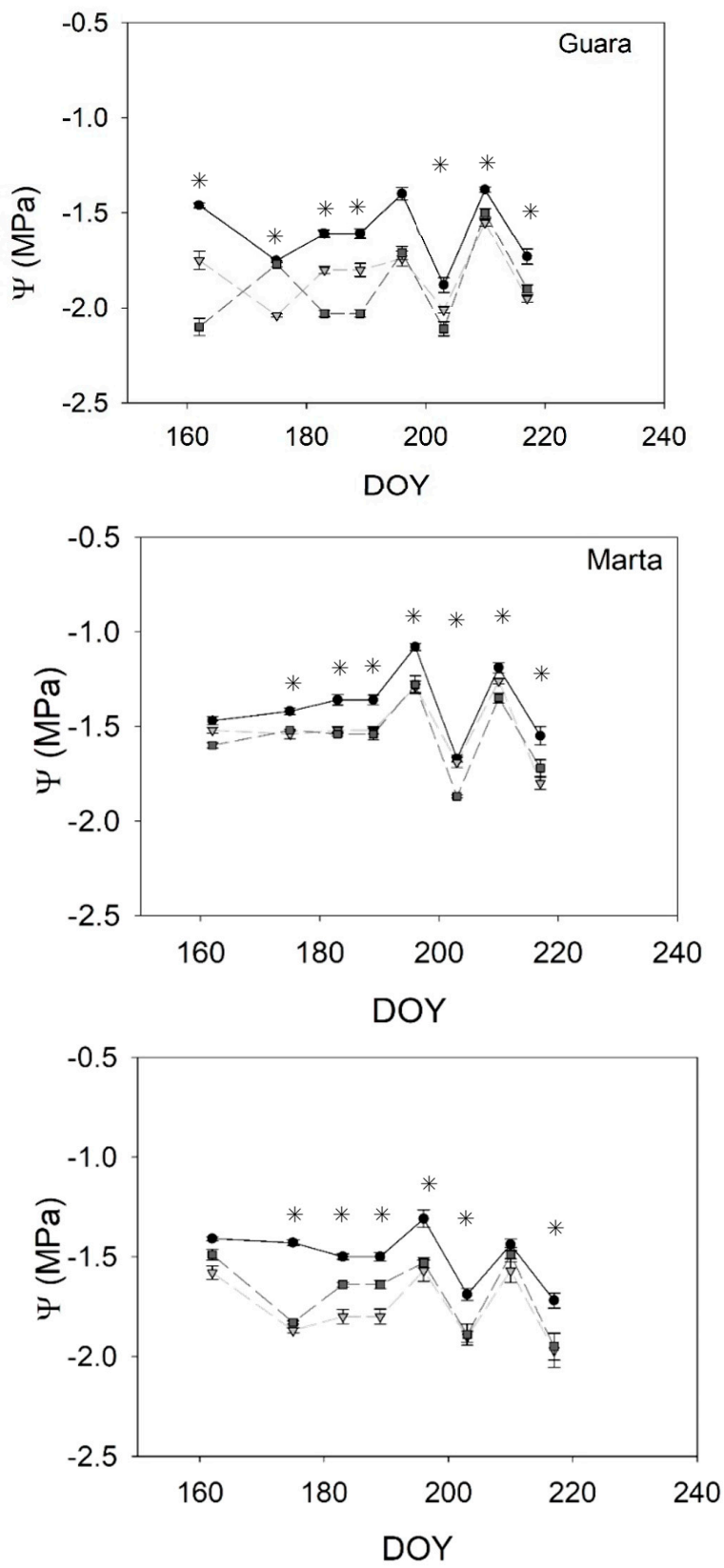

Figure 2. Seasonal dynamics of leaf water potential ( $\left.\Psi_{\text {leaf }}\right)$ during 2018 and 2019. FI, Full irrigated treatment; $\mathrm{SDI}_{75}$, sustained-deficit irrigation at $75 \% \mathrm{IR} ; \mathrm{SDI}_{65}$, sustained-deficit irrigation at $65 \% \mathrm{IR}$, DOY; Day of the year. Vertical bars are standard deviation. Asterisks show the intervals with significant differences between FI and SDI treatments $(p<0.05)$. 

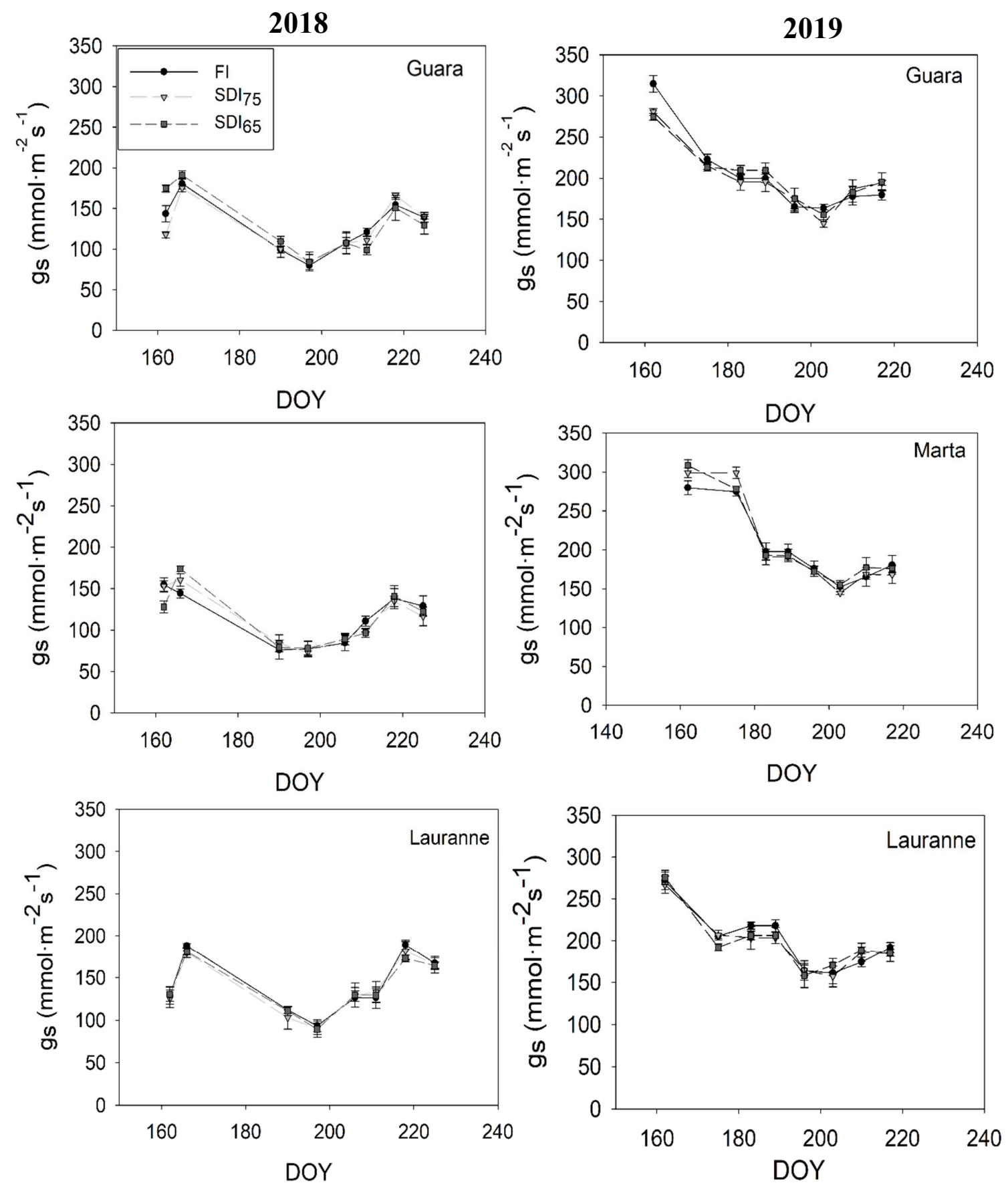

Figure 3. Seasonal dynamics of stomatal conductance $\left(g_{s}\right)$ during 2018 and 2019. FI, Full irrigated treatment; $\mathrm{SDI}_{75}$, sustained-deficit irrigation at $75 \% \mathrm{IR} ; \mathrm{SDI}_{65}$, sustained-deficit irrigation at $65 \% \mathrm{IR}$, DOY; Day of the year. Vertical bars are standard deviation. Asterisks show the intervals with significant differences between FI and SDI treatments $(p<0.05)$. 
Table 1. Effect of deficit irrigation treatment and cultivar on water stress integrals for $S I_{l e a f}$ and $S I_{g s}$.

\begin{tabular}{|c|c|c|c|c|}
\hline & \multicolumn{2}{|c|}{ First Year (2018) } & \multicolumn{2}{|c|}{ Second Year (2019) } \\
\hline & $S I_{\text {leaf }}$ & $S I_{g s}$ & $S I_{\text {leaf }}$ & $S I_{g s}$ \\
\hline ANOVA & (MPa·day) & $\left(\mathrm{mmol} \mathrm{m} \mathrm{m}^{-2} \mathrm{~s}^{-1} \cdot\right.$ day $)$ & (MPa·day) & $\left(\mathrm{mmol} \mathrm{m}{ }^{-2} \mathrm{~s}^{-1}\right.$.day $)$ \\
\hline Irrigation & ns & ns & ns & * \\
\hline Cultivar & $*$ & $*$ & $*$ & $* *$ \\
\hline Irrigation $\times$ cultivar & ns & ns & * & $*$ \\
\hline \multicolumn{5}{|c|}{$\begin{array}{l}\text { Tukey multiple range test } \\
\text { Irrigation }\end{array}$} \\
\hline FI & $198.7 \mathrm{a}$ & $3069 a$ & $188.7 \mathrm{a}$ & $3136 a$ \\
\hline $\mathrm{SDI}_{75}$ & $199.4 \mathrm{a}$ & $3071 \mathrm{a}$ & $197.9 \mathrm{a}$ & $3426 a b$ \\
\hline $\mathrm{SDI}_{65}$ & $197.9 a$ & $3152 a$ & $199.6 a$ & $3758 b$ \\
\hline \multicolumn{5}{|l|}{ Cultivar } \\
\hline Marta & $189.6 \mathrm{~b}$ & $2301 b$ & $187.8 b$ & $2651 b$ \\
\hline Lauranne & $201.6 a$ & $3685 a$ & 194.3ab & $4127 a$ \\
\hline Guara & $204.7 \mathrm{a}$ & $3306 a$ & $204.1 \mathrm{a}$ & $3532 a$ \\
\hline \multicolumn{5}{|l|}{$\begin{array}{l}\text { Irrigation } \times \text { cultivar } \\
\text { cv. Marta }\end{array}$} \\
\hline FI & $190.9 a$ & $2174 a$ & $178.8 \mathrm{~d}$ & $3005 b$ \\
\hline $\mathrm{SDI}_{75}$ & $189.8 \mathrm{a}$ & $2306 a$ & $187.6 \mathrm{c}$ & $2874 b$ \\
\hline $\mathrm{SDI}_{65}$ & $188.2 \mathrm{a}$ & $2422 a$ & 197.2ab & $2075 c$ \\
\hline \multicolumn{5}{|l|}{ cv. Lauranne } \\
\hline FI & $201.9 b$ & $3784 b$ & $193.9 \mathrm{bc}$ & $4151 \mathrm{a}$ \\
\hline $\mathrm{SDI}_{75}$ & $202.9 b$ & $3633 b$ & 197.7ab & $4023 a$ \\
\hline $\mathrm{SDI}_{65}$ & $200.2 b$ & $3639 b$ & $191.3 \mathrm{c}$ & $4207 a$ \\
\hline \multicolumn{5}{|l|}{ cv. Guara } \\
\hline FI & $203.3 b$ & $3249 b$ & $193.5 b c$ & $4089 a$ \\
\hline $\mathrm{SDI}_{75}$ & $205.5 b$ & $3276 b$ & $208.5 a$ & $3381 b$ \\
\hline $\mathrm{SDI}_{65}$ & $205.4 b$ & $3395 b$ & $210.2 a$ & $3127 \mathrm{~b}$ \\
\hline
\end{tabular}

FI, Full irrigated treatment; $\mathrm{SDI}_{75}$, sustained-deficit irrigation at $75 \% \mathrm{IR} ; \mathrm{SDI}_{65}$, sustained-deficit irrigation at $65 \% \mathrm{IR}$. ns, not significant; ${ }^{*}$ and ${ }^{* *}$, significant at $p<0.05$ and $p<0.01$, respectively. Values followed by the same letter within the same column and factor are not significantly different $(p>0.05)$ by Tukey's test.

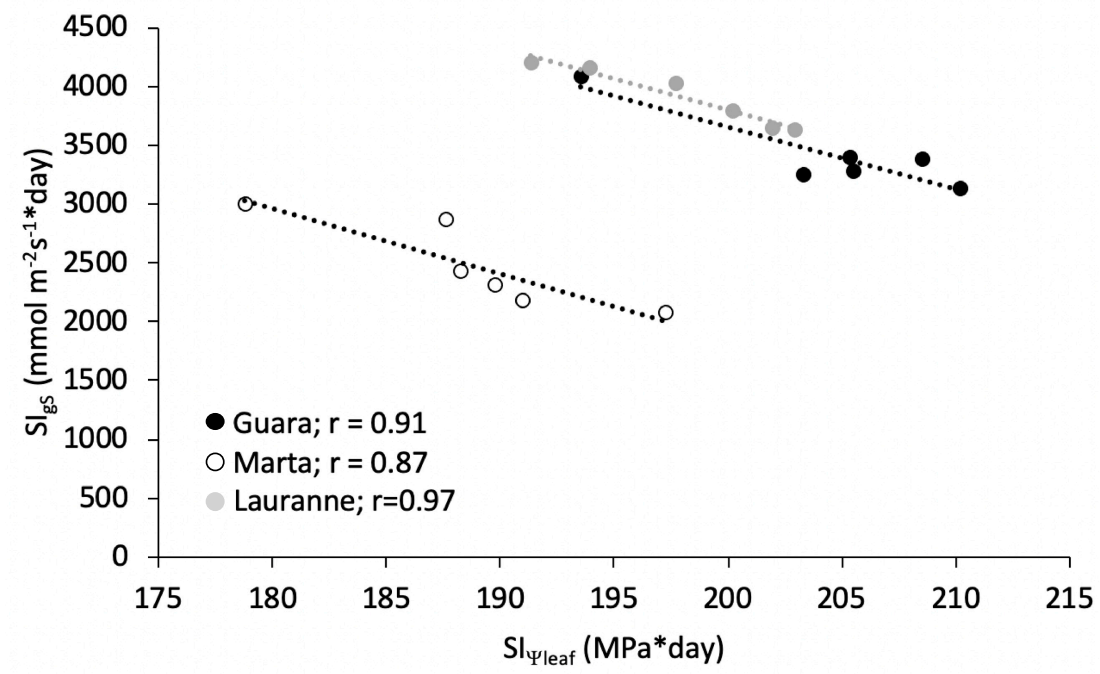

Figure 4. Linear relationships between the stress integral of leaf water potential $\left(S I_{\text {leaf }}\right)$ and stomatal conductance $\left(S I_{g s}\right)$ for cvs. Guara, Marta, and Lauranne. Each point is defined by the average values for each irrigation treatment, season, and cultivar.

According to these results, when physiological response was analyzed by using $S I_{\text {leaf }}$ and $S I_{g s}$, these differences were more evident, this being mostly relevant in comparing the type of cultivars. Considering previous results reported by Gutiérrez-Gordillo et al. [26], cv. Marta was more sensitive to 
water stress in physiological terms, evidencing a stronger stomatal control under RDI strategy. On the contrary, $c v$. Guara triggered physiological mechanisms that were able to maximize the gas-exchange rates by increasing $g_{s}$ and decreasing leaf values. By contrasting these findings with those outlined by García-Tejero et al. [32], declines of leaf encourage to lessen the carbon assimilation rate, disclosing the almond capability in maintaining high $g_{s}$ values even when leaf is close to $-2.5 \mathrm{MPa}$ [33]. Moreover, before reaching important exhaustion in $g_{s}$ rates, reductions in leaf are not accompanied by relevant depletions in $g_{s}$ [32]. This might happen because almond is competent at holding optimum $g_{s}$ and carbon assimilation rates, improving the water-use efficiency, at least under moderate water-stress situations. Therefore, almond reaction to water stress would demand different regulation mechanisms to counteract the adverse impact of water stress as was corroborated with the results of the present study. In addition, according to Fernández et al. [34] and Fu et al. [35], the almond has a lower capability to regulate the stoma under mild water stress situations. Moreover, these findings corroborate with those revealed by García-Tejero et al. [11] who defined two threshold values for $\Psi_{\text {leaf }}$; the first about $-1.4 \mathrm{MPa}$ without reductions for $g_{s}$, and a second of $-2.0 \mathrm{MPa}$, when significant depletions in $g_{s}$ are observed. Also, other authors reported that under moderate water stress conditions the almond tree decreased the leaf rates much more than $g_{s}$, and only when a certain threshold value is reached, significant depletions on photosynthesis rates are detected [36-38].

\subsection{Nut Yield and Irrigation-Water Productivity (IWP)}

Yield and its related components showed results that agreed with the physiological responses observed in the three studied cultivars (Table 2). During the first experimental season, significant differences on kernel yield were observed in $c v$. Guara, with yield reductions around $13 \%$ in $\mathrm{SDI}_{65}$ in comparison to FI treatment. These differences were exclusively reflected in fruits number per tree, with a fruit number depletion similar to that reported on total yield. Something similar happened with $c v$. Marta, with yield reductions around $11 \%$ in $\mathrm{SDI}_{65}$ comparing to FI treatment, as consequence of fruits number reductions of $13.5 \%$ on average. However, these depletions were partially corrected by increasing the kernel unit weight, especially in $\mathrm{SDI}_{75}$. Moreover, no differences on kernel yield were observed for $c v$. Lauranne, with similar results among treatments in all the yield components. FI, Full irrigated treatment; $\mathrm{SDI}_{75}$, Sustained-deficit irrigation at $75 \%$ RI; $\mathrm{SDI}_{65}$, Sustained-deficit irrigation at $65 \%$ RI. Values followed by the same letter within the same row and factor were not significantly different $(p<0.05)$ by Tukey's test.

During the second year, $c v$. Guara showed again significant differences between $\mathrm{SDI}_{65}$ and FI conditions, although in this case $\mathrm{SDI}_{75}$ offered similar productions to those detected under FI; with yield reductions around $8 \%$ and $17 \%$ on $\mathrm{SDI}_{75}$ and $\mathrm{SDI}_{65}$, respectively. These depletions were associated with fruit number reductions roughly $9 \%$ on $\mathrm{SDI}_{75}$ and $32 \%$ on $\mathrm{SDI}_{65}$. It is noticeable that these reductions in the fruits number were partially corrected because of a significant increasing of kernel unit weight on $\mathrm{SDI}_{65}(23 \%$ higher than the obtained value of $\mathrm{FI})$. Something different were the obtained values for $c v$. Marta during the second year, which did not evidence relevant yield losses by effect of SDI strategies. Finally, as it was previously discussed for the first studied season, $c v$. Lauranne registered the best response to SDI strategies, without relevant differences in the studied yield components.

Analysing these results regarding to the irrigation water productivity (IWP, $\mathrm{kg} \cdot \mathrm{m}^{-3}$ ) (Table 3), in the first studied season and within each treatment, cvs. Guara and Marta evidenced similar results, these being $20 \%, 40 \%$, and $31 \%$ higher in $c v$. Lauranne for $\mathrm{FI}, \mathrm{SDI}_{75}$, and $\mathrm{SDI}_{65}$; respectively. Regarding to the effects of water stress, all treatments fixed significant improvements in comparison to the results detected under FI. Thus, comparing the IWP obtained in $\mathrm{SDI}_{65}$ with that registered under FI, the average values for both studied seasons offered improvements on IWP of $31 \%, 36 \%$, and $43 \%$ for Guara, Marta, and Lauranne; respectively. These results were confirmed during the second season. All cultivars offered similar values of IWP for FI and SDI ${ }_{75}$, meanwhile, for the case of $\mathrm{SDI}_{65}$ relevant improvements were detected in cvs. Marta and Lauranne in comparison to $c v$. Guara. Regarding to the effects of water stress, all cultivars registered significant increasing trend under 
SDI strategies, cvs. Lauranne and Marta offering the best response versus $c v$. Guara when sustained water withholdings of $35 \%$ were imposed. These values would be comparable to those reported by Egea et al. [39] for $c v$. Marta $\left(0.25-0.40 \mathrm{~kg} \cdot \mathrm{m}^{-3}\right)$ or Phogat et al. [18] who highlighted that water productivity increased substantially respect to full irrigated trees when SDI strategies were applied.

Table 2. Impact of irrigation strategies on yield components during the studied years.

\begin{tabular}{ccccccc}
\hline Cultivar & \multicolumn{3}{c}{ First Year (2018) } & \multicolumn{3}{c}{ Second Year (2019) } \\
\hline & FI & SDI $_{75}$ & SDI $_{65}$ & FI & SDI $_{75}$ & SDI $_{65}$ \\
\hline Guara & $1929 \mathrm{a}$ & $1659 \mathrm{~b}$ & $1704 \mathrm{~b}$ & $2254 \mathrm{a}$ & $2081 \mathrm{ab}$ & $1871 \mathrm{~b}$ \\
Marta & $1933 \mathrm{a}$ & $1677 \mathrm{~b}$ & $1775 \mathrm{~b}$ & $2218 \mathrm{a}$ & $2209 \mathrm{a}$ & $2243 \mathrm{a}$ \\
Lauranne & $2349 \mathrm{a}$ & $2343 \mathrm{a}$ & $2241 \mathrm{a}$ & $2326 \mathrm{a}$ & $2105 \mathrm{a}$ & $2196 \mathrm{a}$ \\
& \multicolumn{7}{c}{ Ratio (kernel/nut) } \\
Guara & $0.41 \mathrm{a}$ & $0.41 \mathrm{a}$ & $0.41 \mathrm{a}$ & $0.34 \mathrm{a}$ & $0.39 \mathrm{~b}$ & $0.37 \mathrm{~b}$ \\
Marta & $0.32 \mathrm{a}$ & $0.31 \mathrm{a}$ & $0.33 \mathrm{a}$ & $0.34 \mathrm{a}$ & $0.34 \mathrm{a}$ & $0.34 \mathrm{a}$ \\
Lauranne & $0.36 \mathrm{a}$ & $0.36 \mathrm{a}$ & $0.36 \mathrm{a}$ & $0.33 \mathrm{a}$ & $0.33 \mathrm{a}$ & $0.32 \mathrm{a}$ \\
& \multicolumn{7}{c}{ Kernel unit weight (g) } \\
Guara & $1.40 \mathrm{a}$ & $1.40 \mathrm{a}$ & $1.41 \mathrm{a}$ & $0.99 \mathrm{~b}$ & $1.00 \mathrm{~b}$ & $1.22 \mathrm{a}$ \\
Marta & $1.31 \mathrm{a}$ & $1.37 \mathrm{~b}$ & $1.33 \mathrm{a}$ & $1.21 \mathrm{a}$ & $1.18 \mathrm{a}$ & $1.18 \mathrm{a}$ \\
Lauranne & $1.12 \mathrm{a}$ & $1.13 \mathrm{a}$ & $1.13 \mathrm{a}$ & $1.03 \mathrm{a}$ & $1.05 \mathrm{a}$ & $1.08 \mathrm{a}$ \\
Guara & $6611 \mathrm{a}$ & $5688 \mathrm{~b}$ & $5801 \mathrm{~b}$ & $10930 \mathrm{a}$ & $9989 \mathrm{ab}$ & $7363 \mathrm{~b}$ \\
Marta & $7083 \mathrm{a}$ & $5875 \mathrm{~b}$ & $6407 \mathrm{ab}$ & $8799 \mathrm{a}$ & $8984 \mathrm{a}$ & $9125 \mathrm{a}$ \\
Lauranne & $10068 \mathrm{a}$ & $9952 \mathrm{a}$ & $9519 \mathrm{a}$ & $10828 \mathrm{a}$ & $9621 \mathrm{~b}$ & $9758 \mathrm{~b}$ \\
\hline
\end{tabular}

FI, Full irrigated treatment; $\mathrm{SDI}_{75}$, Sustained-deficit irrigation at $75 \% \mathrm{RI}$; $\mathrm{SDI}_{65}$, Sustained-deficit irrigation at $65 \%$ RI. Values followed by the same letter within the same row and factor were not significantly different $(p<0.05)$ by Tukey's test.

Table 3. Irrigation-water productivity $\left(\mathrm{IWP}, \mathrm{kg} \cdot \mathrm{m}^{-3}\right)$ in each cultivar, treatment and studied year.

\begin{tabular}{|c|c|c|c|c|c|c|}
\hline \multirow[t]{3}{*}{ Cultivar } & \multicolumn{3}{|c|}{ First Year (2018) } & \multicolumn{3}{|c|}{ Second Year (2019) } \\
\hline & \multicolumn{6}{|c|}{$\left(\mathrm{kg} \cdot \mathrm{m}^{-3}\right)$} \\
\hline & FI & $\mathrm{SDI}_{75}$ & $\mathrm{SDI}_{65}$ & FI & $\mathrm{SDI}_{75}$ & $\mathrm{SDI}_{65}$ \\
\hline Guara & $0.39 c$ & $0.45 b$ & $0.51 \mathrm{a}$ & $0.29 b$ & $0.36 \mathrm{a}$ & $0.36 \mathrm{a}$ \\
\hline Marta & $0.39 c$ & $0.45 b$ & $0.53 a$ & $0.29 b$ & $0.34 \mathrm{~b}$ & $0.44 a$ \\
\hline Lauranne & $0.47 \mathrm{~b}$ & $0.63 a$ & $0.67 \mathrm{a}$ & $0.30 \mathrm{~b}$ & $0.37 \mathrm{ab}$ & $0.43 a$ \\
\hline
\end{tabular}

FI, Full irrigated treatment; $\mathrm{SDI}_{75}$, Sustained-deficit irrigation at $75 \% \mathrm{IR} ; \mathrm{SDI}_{65}$, Sustained-deficit irrigation at $65 \%$ IR. Values followed by the same letter within the same raw and year were not significantly different $(p<0.05)$ by Tukey's test.

Taking into account the whole of data, $c v$. Guara was the most sensitive cultivar to water stress under sustained-deficit irrigation strategies. This fact is especially noticeable, taking into account that this cultivar evidenced a very positive response when water withholding was applied under RDI strategies during the kernel-filling period [26,28,32]. This contrary response would evidence that the final response to DI strategies would be determined by the added effect of three factors: The cultivar, the water stress, and the irrigation strategy. However, taking into consideration the findings in the present work, when this water stress was applied during the whole irrigation period, it was detected a significant fruit dropping (during the fruit setting period) (Table 2), and ultimately, this determined the final yield with significant reductions linked to less fruit numbers per tree. These results agree with those reported by other authors. In this sense, for a sustained-deficit irrigation study $\left(2500 \mathrm{~m}^{3} \cdot \mathrm{ha}^{-1}\right)$, Alegre et al. [40] in Catalonia (North-Eastern Spain) reported productions for seven-year-old almond plantations of cvs. Guara and Lauranne of 1.65 and $2.02 \mathrm{t} \cdot \mathrm{ha}^{-1}$, respectively. The absolute difference with respect to our findings could mainly be ascribed to the amount of irrigation water applied in water-stressed treatments ( 4250 and $4730 \mathrm{~m}^{3} \cdot \mathrm{ha}^{-1}$ ) and the climatic conditions of South-Western Spain. Likewise, these results would confirm the better response of $c v$. Lauranne in comparison to $c v$. Guara 
under SDI strategies. This is in line with Miarnau et al. [41] who outlined that kernel yield of new almond plantations could be ranged between 1.50 and $2.0 \mathrm{t} \cdot \mathrm{ha}^{-1}$ with water allocations of 2000-3000 and $6000 \mathrm{~m}^{3} \cdot \mathrm{ha}^{-1}$, respectively. In general, the yield potential of almond is highly related to the irrigation amount provided as it was revealed by Miarnau et al. [42]. These authors pointed out that under a SDI strategy with water applications around $2000 \mathrm{~m}^{3} \cdot \mathrm{ha}^{-1}$, the nut yield for cos. Guara and Marta amounted to 1.20 and $1.85 \mathrm{t} \cdot \mathrm{ha}^{-1}$, whereas under FI conditions $\left(\approx 7500 \mathrm{~m}^{3} \cdot \mathrm{ha}^{-1}\right)$ these values were 2.80 and $3.55 \mathrm{t}^{\mathrm{h}} \mathrm{ha}^{-1}$, respectively. Consequently, this fact would suggest that $c v$. Marta would be able to activate a physiological prevention mechanism to mitigate the water stress, yielding more than cv. Guara, as was observed in the present work. Moreover, similar agronomical and physiological responses to water stress of cos. Guara and Lauranne were highlighted by Girona et al. [16].

According to effects of SDI in the fruit unit weight, Alegre et al. [40] reported similar values than those found in the present experiment with kernel unit weights of 1.5 and $1.2 \mathrm{~g}$ for $c v$. Guara and Lauranne. In addition, according to Miarnau et al. [43] kernel unit weight FI conditions for cvs. Guara, Lauranne, and Marta would be around 1.50, 1.20, and $1.50 \mathrm{~g}$, respectively, implying that water stress provoked weight reduction as it was found in the present study. Likewise, it is worth mentioning the improvements in terms of fruit unit weight observed in $c v$. Marta under $\mathrm{SDI}_{75}$ during the first experimental season; and something similar in $c v$. Guara under $\mathrm{SDI}_{65}$, during the second year of this experiment. These results would reinforce the possibility of improving the fruit size when SDI is imposed, this being an added value in relation to fruit marketability and consumer acceptance [44].

\section{Conclusions}

Combining the type of almond cultivars with water stress through deficit irrigation will be vital to reach an equilibrium between water allocations and sustainable nut yields under climate change scenarios. In the framework of the present experiment, the almond response to SDI strategies was cultivar-dependent, and hence, this fact should be considered before designing a proper DI strategy.

The findings allow for a conclusion on the importance of the cultivar when a DI strategy is being applied because different physiological behaviors will promote different responses in terms of yield and its components. In this way, the $c v$. Marta exhibited the most conservative behavior to water stress in physiological terms, which allowed it to obtain very similar productions than those registered under FI conditions. Furthermore, $c v$. Lauranne, despite showing a physiological behavior similar to $c v$. Guara, it was able to reach the best yield values when a moderate-to-severe SDI was applied. Also, according to our findings, $c v$. Guara registered the lesser promising results, with significant yield reductions $(\approx 14 \%)$ when water restrictions around $35 \%$ of irrigation requirements were applied; these being particularly promoted by depletions in the fruit number per tree. That is, $\mathrm{SDI}_{65}$ would be suitable strategies to cvs. Lauranne and Marta, whereas for the case of $c v$. Guara we should select a more moderate SDI strategy (as $\mathrm{SDI}_{75}$ ) or re-consider the application of other more appropriate treatments such as RDI during the kernel-filling period.

Finally, taking into consideration the absence of differences in crs. Lauranne and Marta, and the differing results observed in $c v$. Guara; long-term experiment could be advisable; in order to get a deeper knowledge respect to cumulative effects of more severe water stress strategies imposed during several consecutive seasons. 
Author Contributions: Writing: S.G.-G.; Conception or design: S.G.-G. and I.F.G.-T.; Acquisition, analysis, and interpretation of data: S.G.-G., I.F.G.-T., A.G.E., J.J.A.-A., and F.F.G.; Critical revision of the manuscript for important intellectual content: S.G.-G., I.F.G.-T., V.H.D.Z., and V.H.-S.; Statistical analysis: S.G.-G.; Reagents/materials/analysis tools contribution: S.G.-G., I.F.G.-T., A.G.E., and F.F.G. All authors have read and agreed to the published version of the manuscript.

Funding: Part of this work was sponsored by the research project "Impact of climate change and adaptation measures (INNOVA-Climate)" (AVA.AVA2019.051), Research and Technological Innovation Projects for period 2019-2021 Andalusia moves with Europe.

Acknowledgments: The author S. Gutiérrez-Gordillo has a contract co-financed by National Institute of Agrarian and Food Research and technology (FPI-INIA 2016) and European Social Fund (ESF) “The European Social Fund invests in your future". The authors particularly thank Paco Campos and Juan Luis Viveros from Nutalia SL Comp. for their capable research assistance.

Conflicts of Interest: The authors declare no conflict of interest.

\section{References}

1. Fereres, E.; Soriano, M.A. Deficit irrigation for reducing agricultural water use. J. Exp. Bot. 2007, 58, 147-159. [CrossRef] [PubMed]

2. Sepaskhah, A.R.; Ahmadi, S.H. A review on partial root-zone drying irrigation. Int. J. Plant Prod. 2012, 4, 241-258.

3. Expósito, A.; Berbel, J. Sustainability implications of deficit irrigation in a mature water economy: A case study in Southern Spain. Sustainability 2017, 9, 1144. [CrossRef]

4. Kaya, S.; Evren, S.; Dasci, E.; Adiguzel, M.C.; Yilmaz, H. Effects of different irrigation regimes on vegetative growth, fruit yield and quality of drip-irrigated apricot trees. Afr. J. Biotechnol. 2010, 9, 5902-5907.

5. Sánchez-Rodríguez, L.; Corell, M.; Hernández, F.; Sendra, E.; Moriana, A.; Carbonell-Barrachina, Á.A. Effect of Spanish-style processing on the quality attributes of HydroSOStainable green olives. J. Sci. Food Agric. 2019, 99, 1804-1811. [CrossRef] [PubMed]

6. Torrecillas, A.; Ruiz-Sanchez, M.C.; Del Amor, F.; Leon, A. Seasonal variations on water relations of Amygdalus communis L. under drip irrigated and non irrigated conditions. Plant Soil 1988, 106, 215-220. [CrossRef]

7. Naor, A.; Birger, R.; Peres, M.; Gal, Y.; Elhadi, F.A.; Haklay, A.; Assouline, S.; Schwartz, A. The effect of irrigation level in the kernel dry matter accumulation period on almond yield, kernel dry weight, fruit count, and canopy size. Irrig. Sci. 2018, 36, 1-8. [CrossRef]

8. García Tejero, I.F.; Moriana, A.; Rodríguez Pleguezuelo, C.R.; Durán Zuazo, V.H.; Egea, G. Chapter 12-Sustainable Deficit-Irrigation Management in Almonds (Prunus dulcis L.): Different Strategies to Assess the Crop Water Status. In Water Scarcity and Sustainable Agriculture in Semiarid Environment; García Tejero, I.F., Durán Zuazo, V.H., Eds.; Academic Press: Cambridge, MA, USA, 2018; pp. 271-298.

9. Stewart, W.L.; Fulton, A.E.; Krueger, W.H.; Lampinen, B.D.; Shackel, K.A. Regulated deficit irrigation reduces water use of almonds without affecting yield. Calif. Agric. 2011, 65, 90-95. [CrossRef]

10. Monks, D.P.; Taylor, C.; Sommer, K.; Treeby, M.T. Deficit irrigation of almond trees did not decrease yield. Acta Hortic. 2017, 251-260. [CrossRef]

11. García-Tejero, I.F.; Gutiérrez Gordillo, S.; Souza, L.; Cuadros-Tavira, S.; Durán Zuazo, V.H. Fostering sustainable water use in almond (Prunus dulcis Mill.) orchards in a semiarid Mediterranean environment. Arch. Agron. Soil Sci. 2019, 65, 164-181. [CrossRef]

12. Kang, S.; Zhang, J. Controlled alternate partial root-zone irrigation: Its physiological consequences and impact on water use efficiency. J. Exp. Bot. 2004, 55, 2437-2446. [CrossRef] [PubMed]

13. Egea, G.; González-Real, M.M.; Baille, A.; Nortes, P.A.; Sánchez-Bel, P.; Domingo, R. The effects of contrasted deficit irrigation strategies on the fruit growth and kernel quality of mature almond trees. Irrig. Sci. 2009, 36, 1-8. [CrossRef]

14. Goldhamer, D.A.; Viveros, M.; Salinas, M. Regulated deficit irrigation in almonds: Effects of variations in applied water and stress timing on yield and yield components. Irrig. Sci. 2006, 24, 101-114. [CrossRef]

15. Romero, P.; Botia, P.; Garcia, F. Effects of regulated deficit irrigation under subsurface drip irrigation conditions on vegetative development and yield of mature almond trees. Plant Soil 2004, 260, 169-181. [CrossRef] 
16. Girona, J.; Mata, M.; Marsal, J. Regulated deficit irrigation during the kernel-filling period and optimal irrigation rates in almond. Agric. Water Manag. 2005, 75, 152-167. [CrossRef]

17. Egea, G.; Nortes, P.A.; Domingo, R.; Baille, A.; Pérez-Pastor, A.; González-Real, M.M. Almond agronomic response to long-term deficit irrigation applied since orchard establishment. Irrig. Sci. 2013, 31, 445-454. [CrossRef]

18. Phogat, V.; Skewes, M.A.; Mahadevan, M.; Cox, J.W. Evaluation of soil plant system response to pulsed drip irrigation of an almond tree under sustained stress conditions. Agric. Water Manag. 2013, 118, 1-11. [CrossRef]

19. Alcon, F.; Egea, G.; Nortes, P.A. Financial feasibility of implementing regulated and sustained deficit irrigation in almond orchards. Irrig. Sci. 2013, 31, 931-941. [CrossRef]

20. Karimi, S.; Yadollahi, A.; Arzani, K.; Imani, A.; Aghaalikhani, M. Gas-exchange response of almond genotypes to water stress. Photosynthetica 2015, 53, 29-34. [CrossRef]

21. Palasciano, M.; Logoluso, V.; Lipari, E. Differences in drought tolerance in almond cultivars grown in apulia region (Southeast Italy). Acta Hortic. 2014, 319-324. [CrossRef]

22. Gomes-Laranjo, J.; Coutinho, J.P.; Galhano, V.; Cordeiro, V. Responses of five almond cultivars to irrigation: Photosynthesis and leaf water potential. Agric. Water Manag. 2006, 83, 261-265. [CrossRef]

23. Oliveira, I.; Meyer, A.; Afonso, S.; Gonçalves, B. Compared leaf anatomy and water relations of commercial and traditional Prunus dulcis (Mill.) cultivars under rain-fed conditions. Sci. Hortic. 2018, 229, $226-232$. [CrossRef]

24. Yadollahi, A.; Arzani, K.; Ebadi, A.; Wirthensohn, M.; Karimi, S. The response of different almond genotypes to moderate and severe water stress in order to screen for drought tolerance. Sci. Hortic. 2011, 129, 403-413. [CrossRef]

25. Barzegar, K.; Yadollahi, A.; Imani, A.; Ahmadi, N. Influences of severe water stress on photosynthesis, water use efficiency and proline content of almond cultivars. J. Appl. Hortic. 2012, 14, 33-39. [CrossRef]

26. Gutiérrez-Gordillo, S.; Durán-Zuazo, V.H.; García-Tejero, I. Response of three almond cultivars subjected to different irrigation regimes in Guadalquivir river basin. Agric. Water Manag. 2019, 222, 72-81. [CrossRef]

27. RIA. Red de Información Agroclimática de Andalucía. Instituto Andaluz de Investigación y Formación Agraria y Pesquera. Consejería de Agricultura, Ganadería, Pesca y Desarrollo Sostenible. Junta de Andalucía. Available online: https://ifapa.junta-andalucia.es/agriculturaypesca/ifapa/ria/servlet/FrontController?action= Static\&url=coordenadas.jsp\&c_provincia=41\&c_estacion=19 (accessed on 27 March 2020).

28. López-López, M.; Espadador, M.; Testi, L.; Lorite, I.J.; Orgaz, F.; Fereres, E. Water use of irrigated almond trees when subjected to water deficits. Agric. Water Manag. 2018, 195, 84-93. [CrossRef]

29. Allen, R.G.; Pereira, L.S.; Raes, D.; Smith, M.; W, B. Crop evapotranspiration-Guidelines for computing crop water requirements-FAO Irrigation and drainage paper 56. Irrig. Drain. 1998, 1-15.

30. García-Tejero, I.F.; Hernandez, A.; Rodriguez, V.M.; Ponce, J.R.; Ramos, V.; Muriel, J.L.; Zuazo, V.H.D. Estimating Almond Crop Coefficients and Physiological Response to Water Stress in Semiarid Environments (SW Spain). J. Agric. Sci. Technol. 2015, 17, 1255-1266.

31. Myers, B.J. Water stress integral-a link between short-term stress and long-term growth. Tree Physiol. 1988, 4, 315-323. [CrossRef]

32. García-Tejero, I.F.; Gutiérrez-Gordillo, S.; Ortega-Arévalo, C.; Iglesias-Contreras, M.; Moreno, J.M.; Souza-Ferreira, L.; Durán-Zuazo, V.H. Thermal imaging to monitor the crop-water status in almonds by using the non-water stress baselines. Sci. Hortic. 2018, 238, 91-97. [CrossRef]

33. Hernandez-Santana, V.; Fernández, J.E.; Rodriguez-Dominguez, C.M.; Romero, R.; Diaz-Espejo, A. The dynamics of radial sap flux density reflects changes in stomatal conductance in response to soil and air water deficit. Agric. For. Meteorol. 2016, 218-219, 92-101. [CrossRef]

34. Fernández, J.E. Understanding olive adaptation to abiotic stresses as a tool to increase crop performance. Environ. Exp. Bot. 2014, 103, 158-179. [CrossRef]

35. Fu, X.; Meinzer, F.C. Metrics and proxies for stringency of regulation of plant water status (iso/anisohydry): A global data set reveals coordination and trade-offs among water transport traits. Tree Physiol. 2018, 39, 122-134. [CrossRef] [PubMed]

36. Hernandez-Santana, V.; Rodriguez-Dominguez, C.M.; Fernández, J.E.; Diaz-Espejo, A. Role of leaf hydraulic conductance in the regulation of stomatal conductance in almond and olive in response to water stress. Tree Physiol. 2016, 36, 725-735. [CrossRef] [PubMed] 
37. Rodriguez-Dominguez, C.M.; Buckley, T.N.; Egea, G.; de Cires, A.; Hernandez-Santana, V.; Martorell, S.; Diaz-Espejo, A. Most stomatal closure in woody species under moderate drought can be explained by stomatal responses to leaf turgor. Plant Cell Environ. 2016, 39, 2014-2026. [CrossRef]

38. Espadafor, M.; Orgaz, F.; Testi, L.; Lorite, I.J.; González-Dugo, V.; Fereres, E. Responses of transpiration and transpiration efficiency of almond trees to moderate water deficits. Sci. Hortic. (Amst.) 2017, 225, 6-14. [CrossRef]

39. Egea, G.; Nortes, P.A.; González-Real, M.M.; Baille, A.; Domingo, R. Agronomic response and water productivity of almond trees under contrasted deficit irrigation regimes. Agric. Water Manag. 2010, 97, 171-181. [CrossRef]

40. Alegre Castellví, S.; Miarnau i Prim, X.; Romero Romero, M.; Vargas García, F. Potencial productivo de seis variedades de almendro. Frutic. Prof. 2007, 169, 23-29.

41. Miarnau, X.; Torguet, L.; Batlle, I.; Romero, A.; Rovira, M.; Alegre, S. Comportamiento agronómico y productivo de las nuevas variedades de almendro. Fruticultura 2016, 49, 42-59.

42. Miarnau, X.; Torguet, L.; Batlle, I.; Romero, A.; Rovira, M.; Alegre, S. Resultados agronómicos y productivos de los ensayos IRTA de nuevas variedades de almendro. Irta Jorn. Almendro Ix Ed. 2017, 43-63.

43. Miarnau, X.; Torguet, L.; Batlle, I.; Romero, A.; Rovira, M.; Alegre, S. La revolución del almendro: Nuevas variedades y nuevos modelos productivos. Simp. Nac. Almendro Otros Frutos Secos 2015, 6-27.

44. Lipan, L.; Cano-Lamadrid, M.; Corell, M.; Sendra, E.; Hernández, F.; Stan, L.; Vodnar, D.C.; Vázquez-Araújo, L.; Carbonell-Barrachina, Á.A. Sensory profile and acceptability of hydrosostainable almonds. Foods 2019, 8, 64. [CrossRef] [PubMed]

(C) 2020 by the authors. Licensee MDPI, Basel, Switzerland. This article is an open access article distributed under the terms and conditions of the Creative Commons Attribution (CC BY) license (http://creativecommons.org/licenses/by/4.0/). 